\title{
Individual and herd-level milk ELISA test status for Johne's disease in Ireland after correcting for non-disease-associated variables
}

\author{
Conor G. McAloon, ${ }^{1 *} \odot$ Luke O'Grady, ${ }^{1}$ Bruno Botaro, ${ }^{2} \odot$ Simon J. More, ${ }^{1} \odot$ Michael Doherty, ${ }^{1}$ Paul Whyte, ${ }^{1}$ \\ Søren Saxmose Nielsen, ${ }^{3} \odot$ Lorna Citer, ${ }^{4}$ Kevin Kenny, ${ }^{5} \odot$ David Graham, ${ }^{4} \odot$ and Martin Green ${ }^{6} \odot$ \\ ${ }^{1}$ Section of Herd Health and Animal Husbandry, School of Veterinary Medicine, University College Dublin, Belfield, Dublin 4, Ireland, D04 W6F6 \\ ${ }^{2}$ Dairy Farm Systems Consultant, Auckland, 0612, New Zealand \\ ${ }^{3}$ Department of Veterinary and Animal Sciences, University of Copenhagen, 1850 Frederiksberg Copenhagen, Denmark \\ ${ }^{4}$ Animal Health Ireland, Carrick-on-Shannon, Co. Leitrim, N41 WN27, Ireland \\ ${ }^{5}$ Central Veterinary Research Laboratory, DAFM Laboratories, Backweston, Celbridge, Co. Kildare, W23 X3PH, Ireland \\ ${ }^{6}$ School of Veterinary Medicine and Science, University of Nottingham, Sutton Bonington, United Kingdom, LE12 5RD
}

\begin{abstract}
Antibody-detecting tests for Mycobacterium avium ssp. paratuberculosis (MAP) have low sensitivity and imperfect specificity for detection of infection. Sensitivity increases as the disease progresses. Aside from infection status and stage of disease, several factors affect test performance. These factors have not yet been studied in dairy cows producing lower volumes of milk with higher solids concentration, such as those managed in low-input, pasture-based production systems. Furthermore, the effect of correcting for these associations on individual and herd test status is also unknown. The first objective of this study was to examine the relationship between MAP antibody response in milk and milk yield, somatic cell count (SCC), fat and protein contents, and stage of lactation in dairy cows enrolled in the national Johne's Disease Control Programme (JDCP) in Ireland. The second objective was to examine the effect of correcting the antibody response for these associations on the test status of individual cows and herds, given that individual tests are often used to define a herd's status. Data were extracted for herds in the JDCP from January 2014 to December 2015 inclusive, consisting of 42,657 milk recordings from 18,569 cows across 187 dairy herds. Two linear regression models were constructed to investigate the association between log-transformed MAP sample-to-positive ratio and milk recording data and in primi- and multiparous cows. Days in milk was modeled as a B-spline in each model, and cow and herd were included as random effects. Across both models, natural log-transformed MAP antibody response was negatively associated
\end{abstract}

Received December 6, 2019.

Accepted May 26, 2020.

*Corresponding author: conor.mcaloon@ucd.ie with milk yield, positively associated with protein and fat production, and had a curvilinear association with log-transformed SCC. The association between MAP antibody response and days in milk varied over the course of the lactation. However, when combined, these variables explained only $5.1 \%$ of the variation in the antibody response of the population. After correcting for these associations, 93 multiparous cows and 20 primiparous cows changed category (negative, suspect, or positive). When considered at the herd-test level, out of a total of 531 herd tests, 1 herd changed from negative to positive, and 5 herds changed from positive to negative. This study provides useful information to aid in the interpretation of antibody results for herds testing animals for the presence of MAP infection. At an overall population level, correction of the serological response for non-disease-associated factors has the potential to change the status of only a small number of cows. At the herd level, the proportion of herds changing status was minimal. However, depending on the implications of a herd-level serological diagnosis, consideration should be given to correcting for these non-disease-associated variables within the context of national JD control programs.

Key words: Johne's disease, Mycobacterium avium ssp. paratuberculosis, herd-level testing

\section{INTRODUCTION}

Bovine paratuberculosis (Johne's disease) is a chronic infectious disease of cattle caused by Mycobacterium avium ssp. paratuberculosis (MAP; McAloon et al., 2019a). Infection with MAP has been associated with reduced milk production (McAloon et al., 2016b), higher cull rates (Hendrick et al., 2005), reduced value for culled animals (Kudahl and Nielsen, 2009; Richardson and More, 2009), and possible adverse effects on fertility (Johnson-Ifearulundu et al., 2000). 
In addition to production and economic effects at the farm level, MAP has been associated with a potential zoonotic effect (Waddell et al., 2016). Consequently, major dairy-producing countries have introduced control programs aimed at national control of the disease (Geraghty et al., 2014; Whittington et al., 2019). In general, national disease control programs consist of applying management changes at the farm level to reduce within-herd transmission, as well as identifying and removing infected individuals from the population (McAloon et al., 2019b).

Although there are disagreements regarding its efficacy, test-and-cull remains an important part of many international control programs. In practice, testing most often consists of the application of antibody-detecting tests on either serum or milk. However, antibodydetecting tests for the MAP "infected" state have low sensitivity (Se) and imperfect specificity (Sp), making interpretation of the test results challenging. As animals progress from "infected" to "infectious" and "affected" stages of the disease, the Se of the indirect tests increases (Nielsen and Toft, 2008). However, aside from stage of disease, several other factors are known to affect performance of the test. For example, both stage of lactation (Nielsen and Toft, 2012) and factors such as milk yield, protein concentration, and SCC (Eisenberg et al., 2015) affect the test value.

Studies to investigate the factors affecting the antibody response in individual cows have been conducted on high-yielding dairy cows. However, in a seasonal, pasture-based dairy system such as that operated in Ireland, milk yield is generally lower, with higher protein and fat concentrations (Carty et al., 2017). It is unknown whether associations between milk characteristics and antibody response, as demonstrated in other countries and production systems, hold true for animals with lower milk volumes but higher fat and protein contents. Furthermore, while studies have examined the effect of these variables on a continuous basis, it is unknown what effect correcting for these variables would have when animals and herds are classified using test cut-offs.

To aid in the interpretation of antibody test values, with the aim of classifying the infection status of animals and herds as accurately as possible, it is important to understand the interaction of different factors on the measured antibody response. The first objective of this study, therefore, was to examine the relationship between the MAP antibody response in milk and milk SCC, yield, fat and protein contents, as well as season and stage of lactation in dairy cows enrolled in the national Johne's Disease Control Programme (JDCP) in Ireland. The second objective was to examine the effect of correcting the antibody response for these associations on the test status of individual cows and herds.

\section{MATERIALS AND METHODS}

\section{Data Extraction}

Animal Health Ireland is a not-for-profit organization that was established to coordinate the control of nonregulated animal diseases in Ireland (More et al., 2011). An initial Delphi study identified paratuberculosis as a priority disease for the dairy industry (More et al., 2010). Consequently, a pilot voluntary JDCP was initiated in November 2013 and continued until late 2017 when the Irish Johne's Control Programme was launched.

The pilot phase of the national control program required all enrolled herd owners to test all animals $>24$ mo of age with either a serum ELISA (once per year) or a milk ELISA (twice per year), in addition to a veterinary-administered risk assessment and management plan carried out on farm by a trained practitioner. Data from individual herds are uploaded to the Irish Cattle Breeding Federation (ICBF) database (https:// www.icbf.com/). The ICBF database also includes all milk-recording data for Irish dairy herds.

Data were extracted from the ICBF database for herds in the pilot JDCP from January 2014 to December 2015 inclusive. All herd and animal identifiers were anonymized.

\section{Statistical Analysis}

Only the results from antibody tests conducted using the MAP Idexx Milk ELISA (Mycobacterium paratuberculosis Antibody Test Kit, Idexx Europe, Hoofddorp, the Netherlands) on milk were used. Under the JDCP guidelines, milk samples from cows $<7$ DIM are not used for testing. Records with missing values for SCC, sample-to-positive ratio $(\mathbf{S} / \mathbf{P} \%)$ of the ELISA test, milk yield, calving dates, or recording dates were removed from the data set. Milk records from animals $>305$ DIM were removed before extraction of the data. The results of the MAP ELISA were interpreted according to the manufacturer's guidelines: negative 0-20\%, suspect/inconclusive: $20-30 \%$, positive $>30 \%$. All tests were conducted on samples collected on the day of milk recording. Therefore, all of the test results had corresponding milk recording data for the day of sample collection.

Histograms of each variable were plotted to examine the distribution of values. Non-normally distributed variables ( $\mathrm{SCC}$ and $\mathrm{S} / \mathrm{P} \%$ ) were natural log-trans- 
formed, creating 2 additional variables: $\operatorname{lnSCC}$ and log-transformed $\mathrm{S} / \mathrm{P} \%$. Before transformation, visual inspection of the distribution of $\mathrm{S} / \mathrm{P} \%$ showed a range from -13.5 to $137 \%$. Detailed inspection at the lower end of this distribution demonstrated a higher-thanexpected proportion of readings $<-2 \%$. Further inspection revealed that the majority of values within this range were from a single test date on a single farm. Therefore, all of the data from that farm on that testing date and all other recordings $<-2 \%$ were removed from the data set as erroneous data. To facilitate logtransformation, a constant value $(1.76 \%)$ was first added to the remainder of the values (to ensure all values were greater than zero). Next, the data were split into multiparous and primiparous data sets; for all continuous variables, values outside 2 standard deviations (SD) from the mean were removed as outliers.

The associations between the natural log-transformed $\mathrm{S} / \mathrm{P} \%$ and milk yield, DIM, fat and protein yields, parity, and $\operatorname{lnSCC}$ were investigated with 2 separate mixed-effects linear models: primi- and multiparous cows were modeled separately, because of the different shapes of their lactation curves.

All variables were first plotted against the log-transformed S/P\% to explore the shape of any associations between variables. Those with curvilinear relationships were offered to the model as linear and quadratic terms. Variables with a more complex nonlinear relationship with $\mathrm{S} / \mathrm{P} \%$ were modeled using basis splines. For these variables, the number of knots was chosen to minimize under- and overfitting the data. To achieve this, the number of knots for the spline was varied from 3 to 15 and the $\mathrm{R}^{2}$ and root mean squared error (RMSE) were calculated. Then, for each given number of knots, 10fold cross-validation was carried out. For each fold in the cross-validation, $\mathrm{R}^{2}$ and RMSE were calculated and the mean across the folds taken as the cross-validation $\mathrm{R}^{2}$ and RMSE for that number of knots. The overall $\mathrm{R}^{2}$ and RMSE values for each number of knots were plotted and the number of knots for the final model decided upon based on the number that minimized underfitting (i.e., models with higher overall $\mathrm{R}^{2}$ and lower RMSE were selected) and overfitting (i.e., models that minimized the difference between overall $\mathrm{R}^{2}$, RMSE, and the cross-validation $\mathrm{R}^{2}$ and RMSE were selected).

All variables were first screened in a univariable analysis while accounting for within-animal and withinherd clustering as random effects. A multivariable linear regression model was then constructed using a forward stepwise approach: variables with a univariable $P$-value $<0.20$ were offered to the multivariable model in order of their $P$-value; variables with the lowest $P$-value were added first. After addition of each variable, the $P$-values of all variables in the model were recalculated and those with a $P$-value $<0.05$ retained in the model. Confounding was assessed by examining the change in coefficients for each variable after the addition of each new variable to the model. Variables that resulted in a change in coefficient of any other variables of $>20 \%$ were declared as confounders. These variables were retained in the model irrespective of their $P$-value. All 2 -way interactions of variables significant in the final model were tested, with the exception of DIM. Interactions with DIM were not included to avoid increased complexity and potential overfitting of the model that would arise from all possible combinations of variables with each knot in the spline used to fit DIM. Interactions with a $P$-value $<0.05$ were retained in the final model.

To illustrate the effect of particular variables, logtransformed $\mathrm{S} / \mathrm{P}$ ratios were predicted from the model by varying the values for the variable of interest across the range of values in the population and holding all other variables constant at the median value for the population. To aid interpretation, the predicted logtransformed $\mathrm{S} / \mathrm{P} \%$ was converted to an $\mathrm{S} / \mathrm{P} \%$ by taking the exponential of the predicted value.

Ideally, non-disease-associated animal characteristics should not influence a test value. However, if associations between such characteristics and the $\mathrm{S} / \mathrm{P} \%$ exist, a "corrected S/P\%" can be calculated for each cow by standardizing test scores as if all cows were equal in terms of non-disease-associated variables. To achieve this, a corrected $\mathrm{S} / \mathrm{P} \%$ for each cow reading was calculated by setting all of the cow's characteristics to the median value of the population. First, the S/P\% was predicted for each cow from the final multivariable models. For each cow, the component of the real S/P\% that was unexplained by the model was calculated by subtracting the real $\mathrm{S} / \mathrm{P} \%$ from the predicted $\mathrm{S} / \mathrm{P} \%$. Next, the S/P\% of a "median cow" was predicted by taking the median of the population for each variable in the data set. Finally, this value was added to the unexplained $\mathrm{S} / \mathrm{P} \%$ component of each cow in the data set. These corrected $\mathrm{S} / \mathrm{P} \%$ were classified according to the manufacturer's instructions: $<20 \%$ as negative, $20-30 \%$ as suspect, and $>30 \%$ as positive. Finally, the effect of this correction was assessed by calculating the number of cows that changed category as well as the number of herd tests that changed category, with a herd-test considered positive if at least one animal tested positive.

Tenfold cross-validation was conducted by splitting the data into 10 subsets, each containing $10 \%$ of the data. Ten models were constructed by leaving out one of the subsets in turn and fitting the model to the remaining $90 \%$ of the data. Next, the coefficients of each model were used to predict the values of the remaining $10 \%$ data subset. The mean error and coefficient of 
Table 1. Results of final multivariable models investigating the association between log-transformed SCC and milk yield, log-transformed SCC, milk constituents, parity, and DIM, and log-transformed Mycobacterium avium ssp. paratuberculosis milk ELISA sample-to-positive ratio (S/P, $\%)^{1}$

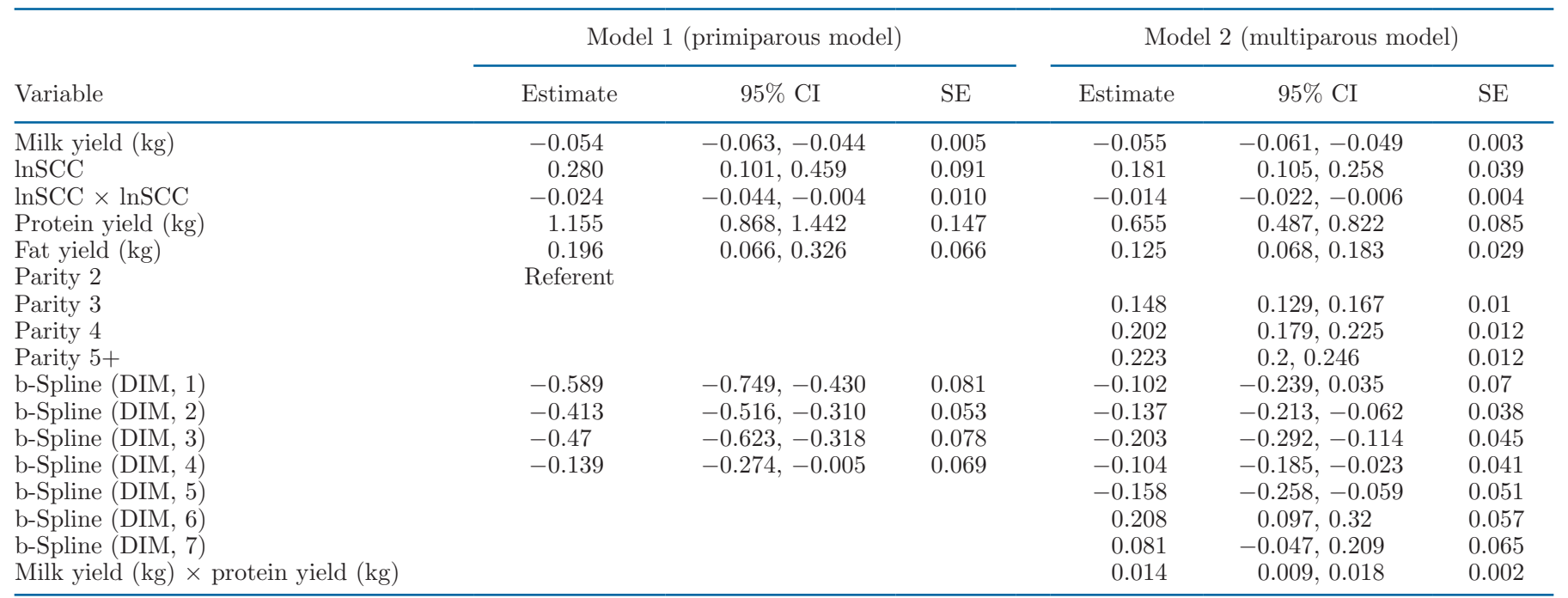

${ }^{1}$ Separate models were constructed for primi- (model 1) and multiparous (model 2) cows.

variation were calculated for each of the 10 models. Finally, the average of the mean error and coefficients of variations of each of the 10 folds in the data were compared with the overall model.

Statistical analysis was conducted in $\mathrm{R}$ Studio version 1.1.419 (R Core Team, 2017) using the "Ime4" (Bates et al., 2015), "dplyr" (Wickham et al., 2019), "lubridate" (Grolemund and Wickham, 2011) and "splines2" (Wang and Yan, 2017) packages. Data visualization was conducted using the "ggplot2" package (Wickham, 2009).

\section{RESULTS}

The initial data set consisted of 42,657 milk recordings from 18,569 cows across 187 dairy herds over the 24-mo period. After removing outliers and missing data, the multiparous data set contained 25,945 milk recordings from 12,701 cows; 6,218 cows had 2 recordings; 3,699 cows had 1 recording; with the remainder having between 3 and 6 recordings (Supplemental Figure S1; https://doi.org/10.3168/jds.2019-18018). Of these, 8,271 records were from second-lactation cows, 6,148 were from third-lactation cows, 4,387 were from fourth-lactation cows, and 7,139 were from cows in their fifth lactation or greater. The primiparous data set contained 9,949 milk recordings from 6,210 cows; 3,518 cows had 2 recordings, 2,585 cows had 1 recording, with the remainder having between 3 and 4 recordings. Descriptive statistics are shown in Supplemental Table S1 (https://doi.org/10.3168/jds.2019-18018) and the distribution of the raw $\mathrm{S} / \mathrm{P}$ ratios is shown in Supplemental Figure S2 (https://doi.org/10.3168/jds .2019-18018).

\section{Model 1 - Primiparous Model}

The results from model 1 are shown in Table 1. Antibody response decreased linearly with increased milk yield; however, the magnitude of this effect was small across the distribution of milk yields in the population: for every 10-L increase in milk yield, the log-transformed $\mathrm{S} / \mathrm{P} \%$ declined by 0.5 . Figure 1 demonstrates that when milk yield in first-lactation animals increased from 10 to $30 \mathrm{~L}$, the $\mathrm{S} / \mathrm{P} \%$ decreased from $6 \%$ to approximately $1.2 \%$.

The $\mathrm{S} / \mathrm{P} \%$ increased in a curvilinear manner in association with increasing SCC. An increase from a logtransformed SCC of 2.5 to 6 was associated with a corresponding increase in $\mathrm{S} / \mathrm{P} \%$ from 3.0 to approximately $3.9 \%$ (Figure 2).

Figure 3 shows the predicted $\mathrm{S} / \mathrm{P} \%$ by stage of lactation. The $\mathrm{S} / \mathrm{P} \%$ decreased rapidly in early lactation up to approximately 100 DIM. After this point, S/P\% increased moderately until approximately 225 DIM, after which it increased until the end of lactation. However, the magnitude of the association was again relatively modest, with most of the variation in $\mathrm{S} / \mathrm{P} \%$ over the course of the lactation ranging from 4 to $6 \%$.

Log-transformed $\mathrm{S} / \mathrm{P} \%$ was positively associated with both protein and fat yields, with each additional 
kilogram of protein and fat associated with 1.2- and 0.20 -unit increases in log-transformed $\mathrm{S} / \mathrm{P} \%$, respectively.

Figures 4 and 5 show predicted $\mathrm{S} / \mathrm{P} \%$ by protein and fat yields, respectively. The $\mathrm{S} / \mathrm{P} \%$ increased in a curvilinear manner with increasing protein yield, whereas $\mathrm{S} / \mathrm{P}$ increased linearly with increasing fat yield.

\section{Model 2 - Multiparous Model}

The results from model 2 are also shown in Table 1. Antibody response also decreased linearly with increasing milk yield: for every 10-L increase in milk yield, the log-transformed S/P\% declined by 0.4 . Figure 1 shows the effect of increasing milk yield from 10 to $40 \mathrm{~L}$ while holding the rest of the variables at the median of the population: the predicted $\mathrm{S} / \mathrm{P} \%$ decreased from $8.7 \%$ at $10 \mathrm{~L}$ to less than $2.5 \%$ at $40 \mathrm{~L}$.

The $\mathrm{S} / \mathrm{P} \%$ increased in a curvilinear manner in association with increased lnSCC. However, the magnitude of this increase was small, with just over a 1-percentage-point increase across the range of SCC values in the population (Figure 2).

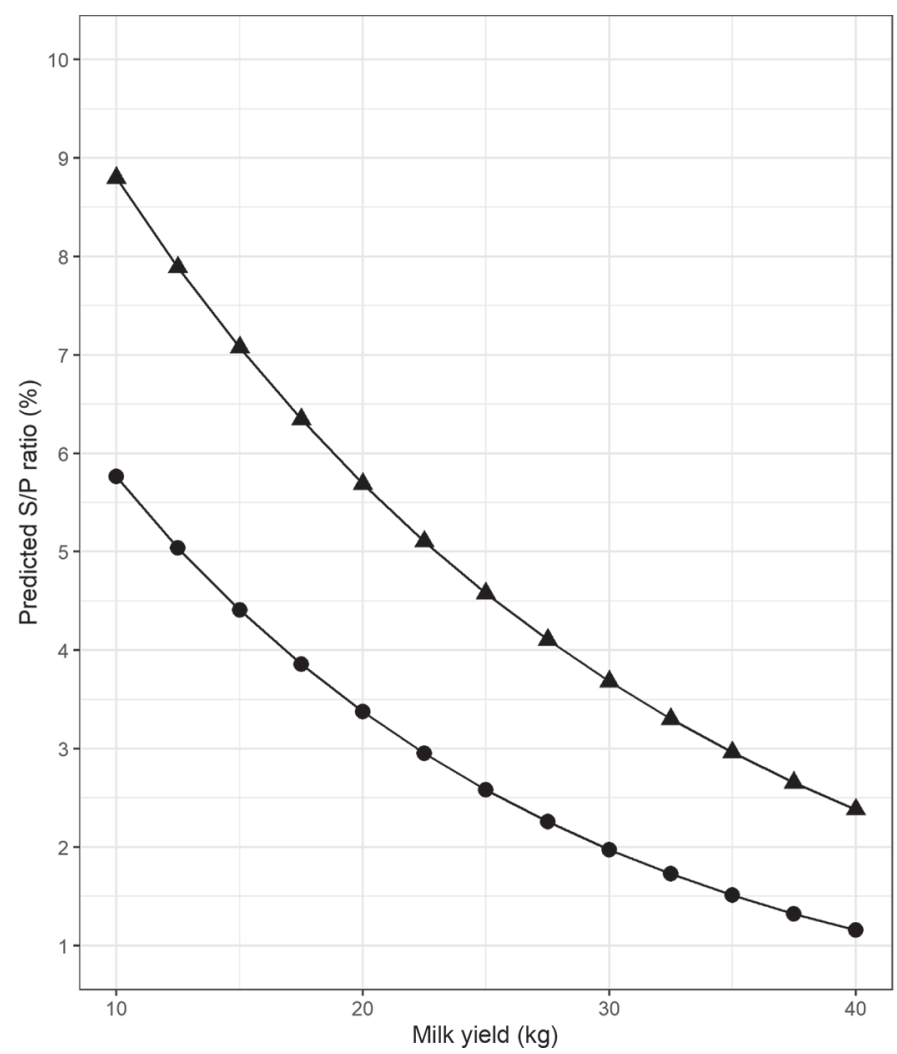

Figure 1. Predicted sample-to-positive ratio $(\mathrm{S} / \mathrm{P}, \%)$ from both primiparous (-) and multiparous ( $\mathbf{\Delta})$ models with increases in milk yield $(\mathrm{kg})$. All other variables in the model were held at the median of the population.
Figure 3 demonstrates the association between DIM and $\mathrm{SP} \%$. The $\mathrm{S} / \mathrm{P} \%$ decreased rapidly in early lactation up to approximately 50 DIM. After this point, the rate of decline in $\mathrm{S} / \mathrm{P} \%$ was reduced to nadir at 120 DIM before increasing toward the end of lactation. However, while there were significant associations between DIM and $\mathrm{S} / \mathrm{P} \%$, the magnitude of these changes was small, with most of the variation in $\mathrm{S} / \mathrm{P} \%$ over the course of the lactation spanning from 4 to $6 \%$.

Log-transformed S/P\% also increased with parity. The log-transformed $\mathrm{S} / \mathrm{P} \%$ was 0.22 units higher for cows in fifth or greater lactation. Fat and protein yields were both positively associated with log-transformed $\mathrm{S} / \mathrm{P} \%$. Each additional 1-kg increase in fat and protein was associated with 0.65 - and 0.13 -unit increases in log-transformed $\mathrm{S} / \mathrm{P} \%$, respectively. A positive interaction was also identified between milk yield and protein yield, indicating that unit increases in either variable were associated with higher increases in logtransformed $\mathrm{S} / \mathrm{P} \%$ as the value of the other variable increased.

Finally, Figures 4 and 5 show predicted $\mathrm{S} / \mathrm{P} \%$ by protein and fat yields, respectively. The $\mathrm{S} / \mathrm{P}$ increased

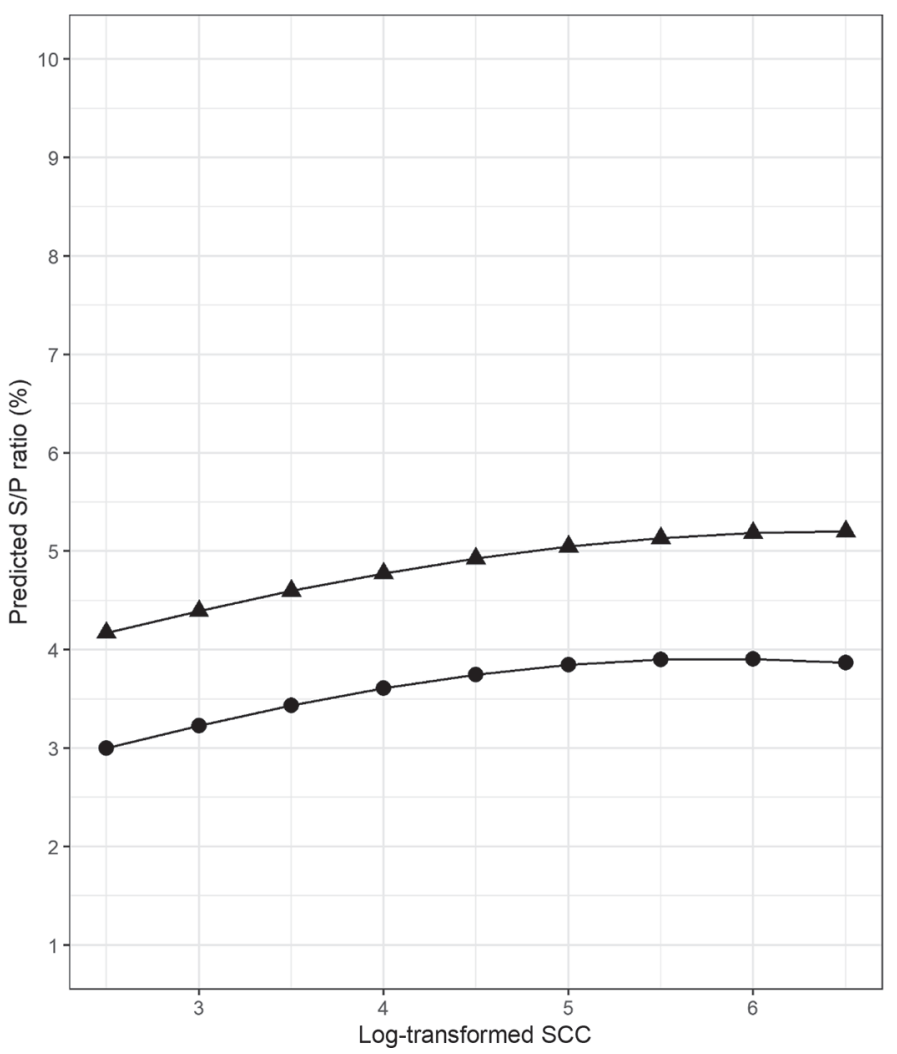

Figure 2. Predicted sample-to-positive ratio (S/P, \%) from both primiparous ( $)$ and multiparous $(\mathbf{\Delta})$ models with increases in logtransformed SCC. All other variables in the model were held at the median of the population. 
in a curvilinear manner with increasing protein yield, whereas S/P increased linearly with increasing fat yield.

\section{Effect of Corrections on Animal and Herd-Test Classification}

Table 2 shows the effect of correcting for non-diseaseassociated variables on the test status of individual animals. On raw interpretation, there were 126 positive tests, 137 suspect tests, and 9,686 negative tests in primiparous animals. After correction, 20 animals changed category: 18 from suspect to negative and 2 from positive to suspect. For multiparous cows, out of 25,945 tested, 447 were positive, 475 were suspect, and 25,023 were negative on raw interpretation. After correction, 92 animals changed category: 53 from suspect to negative, 17 from positive to suspect, 18 from negative to suspect, and 4 from suspect to positive.

Table 3 shows the results of subsequent tests of animals that changed category. In the primiparous model, follow-up testing was available for 8 animals. All 8 animals remained in the category to which they moved after the initial category change. In the multiparous

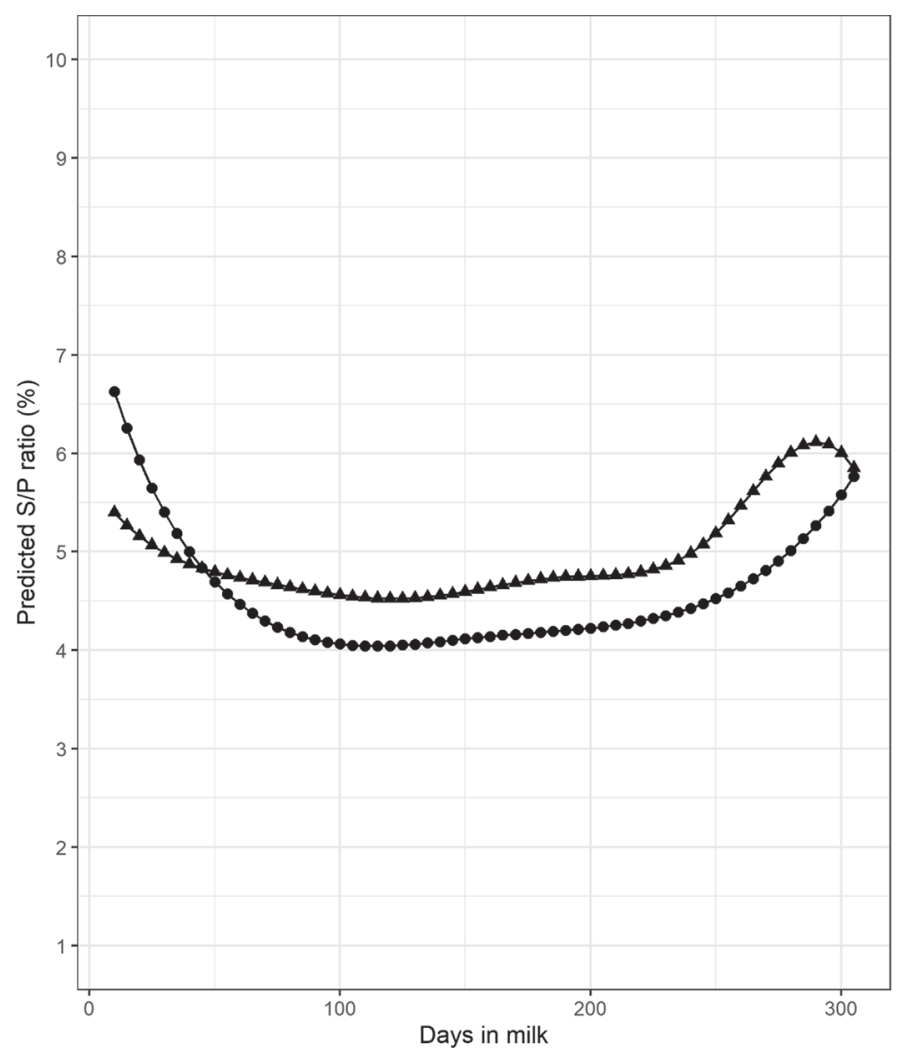

Figure 3. Predicted sample-to-positive ratio (S/P, \%) from both primiparous $(\mathbf{\bullet}$ ) and multiparous $(\boldsymbol{\Lambda})$ models over the course of lactation up to 305 DIM. All other variables in the model were held at the median of the population. model, a subsequent test was available for 44 of the 92 cows that changed category. Overall, 27 cows were negative on a subsequent test, 6 were positive, and 11 were suspect.

Table 4 shows the effect of correcting for non-diseaseassociated variables on herd test status, with herds classified as positive based on one or more animals testing positive. Out of 531 herd tests, 7 changed category, with 2 changing from negative to positive and 5 changing from positive to negative. Of these 7,6 were the result of a single animal changing status; in 1 case, the change in herd status was the result of 2 animals changing status after correction.

\section{Model Cross-Validation}

Overall, the final models explained $5.1 \%$ of the variation in $\operatorname{lnS} / \mathrm{P} \%$ with a mean absolute error (MAE) of $0.50 \mathrm{lnS} / \mathrm{P} \%$. Tenfold cross-validation did not reveal overfitting of the models. In the multiparous models, the mean $\mathrm{R}^{2}$ across each of the cross validations was $4.7 \%\left(\mathrm{R}^{2}\right.$ for full multiparous model $\left.=4.6 \%\right)$, with an average MAE of 0.51 (MAE for full model $=0.51$ ).

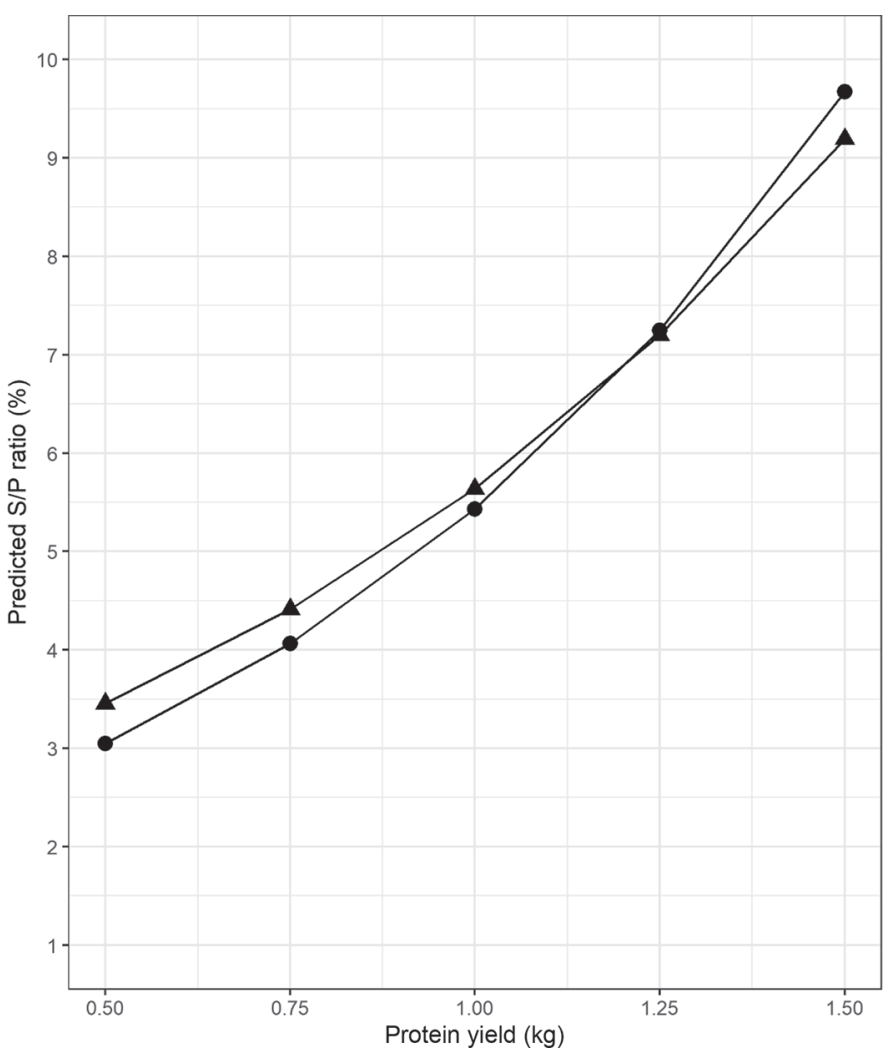

Figure 4. Predicted sample-to-positive ratio (S/P, \%) from both primiparous $(\bullet)$ and multiparous $(\mathbf{\Lambda})$ models with increases in protein yield $(\mathrm{kg})$. All other variables in the model were held at the median of the population. 
Table 2. Effect of correcting for non-disease-associated variables on Mycobacterium avium ssp. paratuberculosis milk ELISA status of individual animals $^{1}$

\begin{tabular}{|c|c|c|c|c|c|c|c|c|}
\hline \multirow{2}{*}{ Corrected result } & \multicolumn{8}{|c|}{ Raw result } \\
\hline & \multicolumn{4}{|c|}{ Primiparous model } & \multicolumn{4}{|c|}{ Multiparous model } \\
\hline Negative & 9,686 & 18 & 0 & 9,704 & 25,005 & 53 & 0 & 25,058 \\
\hline Suspect & 0 & 119 & 2 & 121 & 18 & 418 & 17 & 453 \\
\hline Positive & 0 & 0 & 124 & 124 & 0 & 4 & 430 & 434 \\
\hline
\end{tabular}

${ }^{1}$ Corrected results were predicted from the model after correcting each cow to the median of the population for each of the variables in the final model.

In the primiparous model, the mean $\mathrm{R}^{2}$ across each of the cross validations was $4.5 \%$ (overall $\mathrm{R}^{2}$ for full primiparous model $4.3 \%$ ), with an average 0.51 (MAE for full model $=0.48$ ).

\section{DISCUSSION}

Despite questions regarding its efficacy, test-andcull remains an important aspect of paratuberculosis

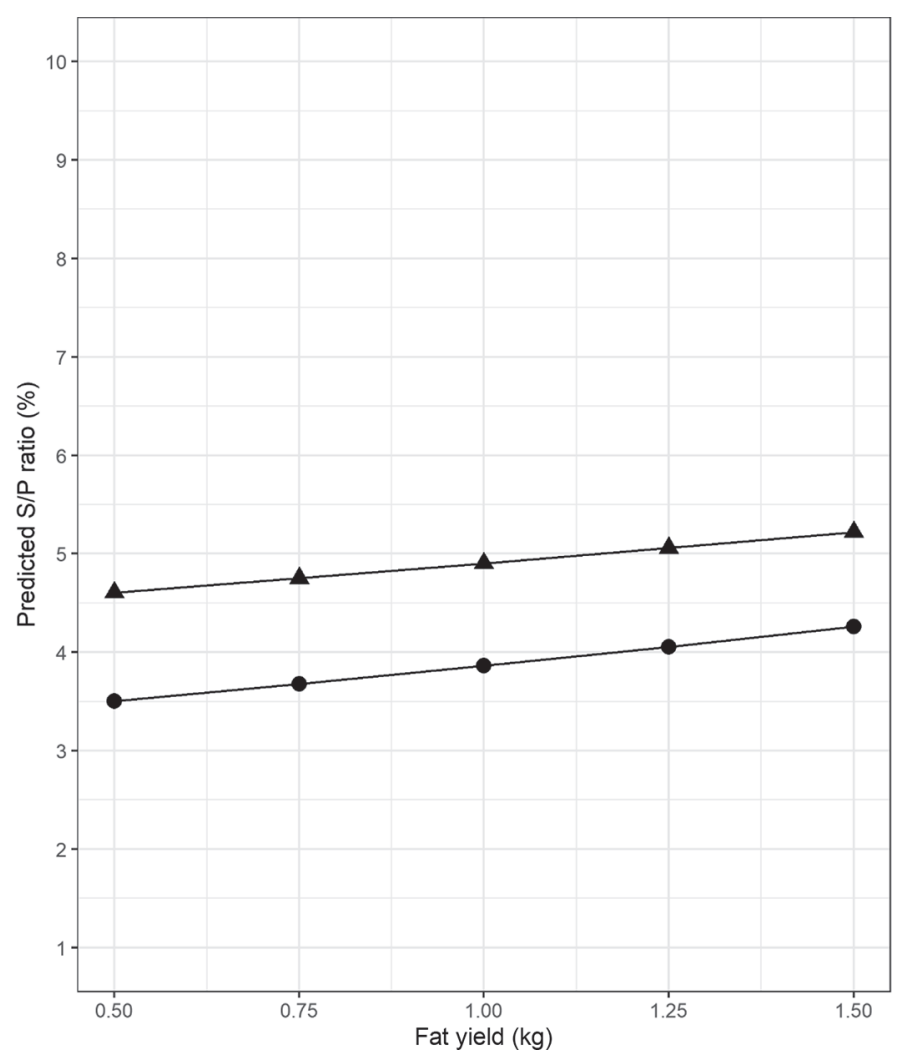

Figure 5. Predicted sample-to-positive ratio (S/P, \%) from both primiparous $(\bullet)$ and multiparous $(\mathbf{\Lambda})$ models with increases in fat yield $(\mathrm{kg})$. All other variables in the model were held at the median of the population. control programs at the farm level (McAloon et al., 2019b). However, the present study demonstrated that a number of factors other than infection status were associated with the antibody response in milk.

Milk yield at test day was negatively associated with milk ELISA S/P\%, which agrees with previous studies. Eisenberg et al. (2015) found that for each $5-\mathrm{kg}$ increase in milk yield, the natural log-transformed $\mathrm{S} / \mathrm{P} \%$ decreased by 0.12 . In our study, the comparable decreases in milk production were 0.22 and 0.25 for multi- and primiparous animals, respectively. This observation raises an interesting question regarding previous studies that aimed to quantify the effect of infection on milk production when case definitions were based on milk ELISA. For those studies, a decrease in milk production associated with infection status would be expected. However, our study raises the possibility of a contradictory and reverse association; that is, cows with higher milk production have lower antibody values irrespective of infection status. This observation may explain part of the discrepancy between production losses when infection status is classified using pathogen detection methods versus antibody detecting methods (McAloon et al., 2016b).

The association between DIM and antibody response has also been observed in previous studies. Nielsen et al. (2002) found that the odds of being positive on milk ELISA were highest in the first 2 wk of lactation, declining to a nadir at 13 to 28 wk in lactation before increasing toward the end of lactation. Subsequently, the same authors found that the increase in antibody response at the start of lactation was most pronounced during the first 7 DIM (Nielsen and Toft, 2012).

Eisenberg et al. (2015) modeled DIM as a categorical variable, rather than as a continuous variable, as was done in the current study. Nevertheless, a comparison of the results is noteworthy. Extrapolating from the categorical coefficients in their study, antibody response was highest in the first month of lactation, declining to a nadir between 211 and $240 \mathrm{~d}$, with an increase toward 
Table 3. Result of subsequent test for cows that changed category as a result of correcting for non-diseaseassociated variables associated with the Mycobacterium avium ssp. paratuberculosis milk ELISA

\begin{tabular}{|c|c|c|c|c|c|c|}
\hline \multirow{3}{*}{$\begin{array}{l}\text { Change category } \\
\text { (raw to corrected) }\end{array}$} & \multicolumn{6}{|c|}{ Subsequent test result } \\
\hline & \multicolumn{3}{|c|}{ Primiparous model } & \multicolumn{3}{|c|}{ Multiparous model } \\
\hline & Negative & Suspect & Positive & Negative & Suspect & Positive \\
\hline Negative to suspect & 0 & 0 & 0 & 9 & 3 & 2 \\
\hline Positive to suspect & 0 & 1 & 0 & 5 & 0 & 1 \\
\hline Suspect to negative & 7 & 0 & 0 & 12 & 6 & 3 \\
\hline Suspect to positive & 0 & 0 & 0 & 1 & 2 & 0 \\
\hline
\end{tabular}

the end of lactation. More recently, a US study found that the highest antibody response occurred during the first 60 DIM. However, the test value did not increase toward the end of lactation (Machado et al., 2018).

The reason for this observed response is not entirely clear. Nielsen and Toft (2012) hypothesized that the increase in antibody response in the first 7 DIM was associated with binding of nonspecific proteins to the ELISA plate, resulting in a falsely elevated result, although not all of the effect of yield was accounted for in that study. Other authors have related this observation to milk yield (Eisenberg et al., 2015). On a univariable analysis, it could be assumed that much of the effect of DIM is exerted through its effect on milk yield and solids concentration. However, because milk yield on test day was included as a covariate, this study suggests that DIM exerts an effect on antibody response outside of the effect of milk yield and fat and protein contents. Interestingly, an earlier study examining raw IgG content by stage of lactation found that IgG concentration peaked from 15 to 49 DIM, reached a nadir from 110 to 219 DIM, before increasing again toward the end of lactation, while accounting for milk yield as a fixed effect in the multivariable model (Liu et al., 2009).

We found a curvilinear association between milk SCC and $\mathrm{S} / \mathrm{P} \%$, with the largest increase in $\mathrm{S} / \mathrm{P} \%$ observed across the lower range of SCC values. Recently, a similar association was identified in US dairy cows. When modeling SCC as a categorical variable, there was an almost linear association between increases in SCC category and S/P\% (Machado et al., 2018). Similar to

Table 4. Effect of correcting for non-disease-associated variables associated with the Mycobacterium avium ssp. paratuberculosis milk ELISA sample-to-positive ratio on herd-test status ${ }^{1}$

\begin{tabular}{lcc}
\hline & \multicolumn{2}{c}{ Raw result } \\
\cline { 2 - 3 } Corrected result & Negative & Positive \\
\hline Negative & 308 & 5 \\
Positive & 2 & 216
\end{tabular}

${ }^{1} \mathrm{~A}$ herd test was considered positive if at least one animal tested positive.

Journal of Dairy Science Vol. 103 No. 10, 2020 our study, that association was also found across the lower range of SCC values, in a range that is generally assumed to not indicate mastitis (i.e., $<200$ cells $/ \mathrm{mL}$ ). Frequently, it has been suggested that animals with MAP infection are likely to succumb to other infections such as mastitis. However, evidence for this association has been weak (McAloon et al., 2019a). Given that the association was primarily observed among the low range of SCC values, we present an alternative hypothesis that this observed association is not necessarily due to MAP infection resulting in immunosuppression and subsequent mastitis infection, but that factors that increase SCC at the cow level, irrespective of mastitis status, may also increase the MAP antibody response, irrespective of MAP infection status. Interestingly, this relationship has been observed for other diseases; for example, ostertagiosis (Sanchez et al., 2004).

The associations observed between milk solids content and antibody response are also interesting. Both fat and protein contents were associated with an increase in log-transformed S/P\%. Nielsen and Toft (2012) observed that antibody responses were increased in very early lactation. Those authors hypothesized that this was the result of nonspecific protein binding to the plate, resulting in false-positive test results. Because Irish cattle generally have higher solids concentration than production systems in other countries (Geary et al., 2010), it is possible that this effect is exacerbated in Irish dairy cattle.

The log-transformed $\mathrm{S} / \mathrm{P} \%$ was associated with parity, being 0.22 units higher in lactation $5+$ compared with lactation 2 . When all other variables were held at the median of the population, this equated to just greater than a 1-percentage-point increase in $\mathrm{S} / \mathrm{P} \%$. The association between increasing parity and $\mathrm{S} / \mathrm{P} \%$ may, in part, be explained by the fact that older animals are more likely to be seropositive. However, many of the comparisons in this analysis are based on animals that were test negative. Therefore, this association is likely independent of test status and potentially independent of infection status. An additional explanation for this could be that older cows produce milk with 
higher levels of immunoglobulin, as has been observed in other studies (Liu et al., 2009). It has been hypothesized that this relationship could result from greater levels of inflammation in the mammary gland of older cows, resulting in greater leakage of IgG from serum into milk in these animals (Sanchez et al., 2004).

Although these variables were statistically significant, the final models had $\mathrm{R}^{2}$ values of 4 to $5 \%$. The finding that only a small proportion of the variation in $\ln \mathrm{S} / \mathrm{P} \%$ was explained by factors not directly associated with infection was perhaps expected, given that the test is designed to detect differences in MAP infection status only. Nonetheless, correcting for these non-disease-associated factors has the potential effect of changing the status of several animals. Although, as a proportion of the overall animals tested, the proportion changing category was quite small, it was much higher when considered as a proportion of animals testing non-negative on raw interpretation. Furthermore, the effect of correcting animals at a herd level may be higher given that a single animal might change the test status for an entire herd. In practice, these factors need to be balanced against the potential disadvantages of correcting test results, such as the feasibility of its implementation and the practical difficulty in correcting, managing, and communicating the output of such results. Ultimately, whether test results should be corrected should be considered in the context of the implications of such a herd test.

Although we use the term "non-disease-associated" and "not directly associated with disease status" in this study, many of these factors are interrelated to some degree. For example, disease status may play a role in milk production, which may then affect the $\mathrm{S} / \mathrm{P}$ ratio. Were the true disease status of individuals known, it would be possible to estimate these relationships after correcting for disease status. However, accurately classifying the paratuberculosis infection status of individuals is problematic (McAloon et al., 2019a) and we did not have adequate data to carry out this analysis. It should be noted that the apparent animal-level prevalence in our data set was $1.8 \%$. Previously, the true animal-level prevalence of paratuberculosis infection in Ireland was estimated at 3\% (McAloon et al., 2016a). Therefore, these findings could be expected to be reflective of uninfected cows. The relationships between milk ELISA and milk yield, SCC, fat, and protein are interesting in the management of MAP infections in itself, and the biases arising are those the farmer has to deal with when interpreting the results.

It should also be noted that cut-offs for a particular test are chosen to optimize detection for the population that the test is applied to. In this case, we applied the same cut-off points to the corrected values as were advised for the uncorrected values. If correction were to become part of normal practice, then cut-off points may need to be optimized for corrected values.

We chose to model primiparous and multiparous cows separately. This decision was made given the different shape of the lactation curve recognized in primiparous cows. An alternative method would have been to include both cohorts in the same model. However, to account for the different shape of the lactation curve in this group, we would have had to include an interaction between each of the knots in the spline for DIM with each parity group. Because of concerns around overfitting and the increasing complexity of the model, we chose the simpler approach of using 2 separate models.

Finally, this study used data that only included recordings up to 305 DIM. The availability of data from later stages of lactation may have aided in the generalizability of the study. However, an important focus of this study was to understand these associations in seasonal calving systems. In such systems, lactations do not regularly exceed $305 \mathrm{~d}$.

\section{CONCLUSIONS}

This study provides useful information to aid in the interpretation of antibody-detecting test results for the presence of MAP infection. The MAP antibody response in milk in Irish dairy cattle was negatively associated with milk yield and positively associated with milk fat and protein yields and log-transformed SCC. The effect of DIM varied over the course of the lactation. At the overall population level, correction of the antibody response for non-disease-associated factors has the potential to change the status of only a small number of cows. At the herd level, the proportion of herds changing status was minimal. However, depending on the implications of a herd-level serological diagnosis, consideration should be given to correcting for these non-disease-associated variables within the context of national control programs.

\section{ACKNOWLEDGMENTS}

This research did not receive any specific funding. The authors have not stated any conflicts of interest.

\section{REFERENCES}

Bates, D., M. Mächler, B. Bolker, and S. Walker. 2015. Fitting linear mixed-effects models using lme4. J. Stat. Softw. 67:1-48. https:// doi.org/10.18637/jss.v067.i01.

Carty, C. I., A. G. Fahey, M. R. Sheehy, S. Taylor, I. J. Lean, C. G. McAloon, L. O'Grady, and F. J. Mulligan. 2017. The prevalence, temporal and spatial trends in bulk tank equivalent milk fat depression in Irish milk recorded herds. Ir. Vet. J. 70:14. https://doi .org/10.1186/s13620-017-0092-y. 
Eisenberg, S. W. F., E. Veldman, V. P. Rutten, and A. P. Koets. 2015. A longitudinal study of factors influencing the result of a $\mathrm{Myco-}$ bacterium avium ssp. paratuberculosis antibody ELISA in milk of dairy cows. J. Dairy Sci. 98:2345-2355. https://doi.org/10.3168/ jds.2014-8380.

Geary, U., N. Lopez-Villalobos, D. J. Garrick, and L. Shalloo. 2010. Development and application of a processing model for the Irish dairy industry. J. Dairy Sci. 93:5091-5100. https://doi.org/10 $.3168 / \mathrm{jds} .2010-3487$.

Geraghty, T., D. A. Graham, P. Mullowney, and S. J. More. 2014. A review of bovine Johne's disease control activities in 6 endemically infected countries. Prev. Vet. Med. 116:1-11. https://doi.org/10 .1016/j.prevetmed.2014.06.003.

Grolemund, G., and H. Wickham. 2011. Dates and times made easy with lubridate. J. Stat. Softw. 40:1-25. https://doi.org/10.18637/ jss.v040.i03.

Hendrick, S. H., D. F. Kelton, K. E. Leslie, K. D. Lissemore, M. Archambault, and T. F. Duffield. 2005. Effect of paratuberculosis on culling, milk production, and milk quality in dairy herds. J. Am. Vet. Med. Assoc. 227:1302-1308. https://doi.org/10.2460/javma 2005.227.1302.

Johnson-Ifearulundu, Y. J., J. Kaneene, D. Sprecher, J. Gardiner, and J. Lloyd. 2000. The effect of subclinical Mycobacterium paratuberculosis infection on days open in Michigan, USA, dairy cows. Prev. Vet. Med. 46:171-181. https://doi.org/10.1016/S0167 $-5877(00) 00145-8$.

Kudahl, A. B., and S. S. Nielsen. 2009. Effect of paratuberculosis on slaughter weight and slaughter value of dairy cows. J. Dairy Sci. 92:4340-4346. https://doi.org/10.3168/jds.2009-2039.

Liu, G. L., J. Q. Wang, D. P. Bu, J. B. Cheng, C. G. Zhang, H. Y. Wei, L. Y. Zhou, Z. F. Zhou, H. Hu, and X. L. Dong. 2009. Factors affecting the transfer of immunoglobulin G1 into the milk of Holstein cows. Vet. J. 182:79-85. https://doi.org/10.1016/j.tvjl 2008.05.019.

Machado, G., K. Kanankege, V. Schumann, S. Wells, A. Perez, and J. Alvarez. 2018. Identifying individual animal factors associated with Mycobacterium avium subsp. paratuberculosis (MAP) milk ELISA positivity in dairy cattle in the Midwest region of the United States. BMC Vet. Res. 14:28.

McAloon, C. G., M. L. Doherty, P. Whyte, L. O'Grady, S. J. More, L. L. M. Messam, M. Good, P. Mullowney, S. Strain, and M. J. Green. 2016a. Bayesian estimation of prevalence of paratuberculosis in dairy herds enrolled in a voluntary Johne's Disease Control Programme in Ireland. Prev. Vet. Med. 128:95-100. https://doi .org/10.1016/j.prevetmed.2016.04.014.

McAloon, C. G., S. Roche, C. Ritter, H. W. Barkema, P. Whyte, S. J. More, L. O'Grady, M. J. Green, and M. L. Doherty. 2019a. A review of paratuberculosis in dairy herds - Part 1: Epidemiology. Vet. J. 246:59-65. https://doi.org/10.1016/j.tvjl.2019.01.010.

McAloon, C. G., S. Roche, C. Ritter, H. W. Barkema, P. Whyte, S. J. More, L. O'Grady, M. J. Green, and M. L. Doherty. 2019b. A review of paratuberculosis in dairy herds-Part 2: On-farm control. Vet. J. 246:54-58. https://doi.org/10.1016/j.tvjl.2019.01.009.

McAloon, C. G., P. Whyte, S. J. More, M. J. Green, L. O'Grady, A. Garcia, and M. L. Doherty. 2016b. The effect of paratuberculosis on milk yield - A systematic review and meta-analysis. J. Dairy Sci. 99:1449-1460. https://doi.org/10.3168/jds.2015-10156.

More, S. J., M. L. Doherty, L. Downey, K. McKenzie, C. Devitt, and J. O'Flaherty. 2011. Animal Health Ireland: Providing national leadership and coordination of non-regulatory animal health issues in Ireland. Rev. Sci. Tech. 30:715-723. https://doi.org/10.20506/ rst.30.3.2071.

More, S. J., K. McKenzie, J. O'Flaherty, M. L. Doherty, A. R. Cromie, and M. J. Magan. 2010. Setting priorities for non-regulatory animal health in Ireland: Results from an expert Policy Delphi study and a farmer priority identification survey. Prev. Vet. Med. 95:198-207. https://doi.org/10.1016/j.prevetmed.2010.04.011.
Nielsen, S. S., C. Enevoldsen, and Y. T. Gröhn. 2002. The Mycobacterium avium ssp. paratuberculosis ELISA response by parity and stage of lactation. Prev. Vet. Med. 54:1-10. https://doi.org/10 .1016/S0167-5877(02)00008-9.

Nielsen, S. S., and N. Toft. 2008. Ante mortem diagnosis of paratuberculosis: a review of accuracies of ELISA, interferon- $\gamma$ assay and faecal culture techniques. Vet. Microbiol. 129:217-235. https://doi .org/10.1016/j.vetmic.2007.12.011.

Nielsen, S. S., and N. Toft. 2012. Effect of days in milk and milk yield on testing positive in milk antibody ELISA to Mycobacterium avium ssp. paratuberculosis in dairy cattle. Vet. Immunol. Immunopathol. 149:6-10. https://doi.org/10.1016/j.vetimm.2012.05.013.

R Core Team. 2017. R: A language and environment for statistical computing. R Foundation for Statistical Computing, Vienna, Austria. https://www.R-project.org/.

Richardson, E., and S. J. More. 2009. Direct and indirect effects of Johne's disease on farm and animal productivity in an Irish dairy herd. Ir. Vet. J. 62:526-532. https://doi.org/10.1186/2046-0481-62 $-8-526$.

Sanchez, J., F. Markham, I. Dohoo, J. Sheppard, G. Keefe, and K. Leslie. 2004. Milk antibodies against Ostertagia ostertagi: Relationships with milk $\operatorname{IgG}$ and production parameters in lactating dairy cattle. Vet. Parasitol. 120:319-330. https://doi.org/10.1016/ j.vetpar.2004.01.010.

Waddell, L., A. Rajić, K. Stärk, and S. A. McEwen. 2016. Mycobacterium avium ssp. paratuberculosis detection in animals, food, water and other sources or vehicles of human exposure: A scoping review of the existing evidence. Prev. Vet. Med. 132:32-48. https://doi .org/10.1016/j.prevetmed.2016.08.003.

Wang, W., and J. Yan. 2017. splines2: Regression spline functions and classes. $\mathrm{R}$ package version 0.2.7. https://CRAN.R-project.org/ package $=$ splines 2 .

Whittington, R., K. Donat, M. F. Weber, D. Kelton, S. S. Nielsen, S. Eisenberg, N. Arrigoni, R. Juste, J. L. Sáez, N. Dhand, A. Santi, A. Michel, H. Barkema, P. Kralik, P. Kostoulas, L. Citer, F. Griffin, R. Barwell, M. A. S. Moreira, I. Slana, H. Koehler, S. V. Singh, H. S. Yoo, G. Chávez-Gris, A. Goodridge, M. Ocepek, J. Garrido, K. Stevenson, M. Collins, B. Alonso, K. Cirone, F. Paolicchi, L. Gavey, M. T. Rahman, E. de Marchin, W. Van Praet, C. Bauman, G. Fecteau, S. McKenna, M. Salgado, J. Fernández-Silva, R. Dziedzinska, G. Echeverría, J. Seppänen, V. Thibault, V. Fridriksdottir, A. Derakhshandeh, M. Haghkhah, L. Ruocco, S. Kawaji, E. Momotani, C. Heuer, S. Norton, S. Cadmus, A. Agdestein, A. Kampen, J. Szteyn, J. Frössling, E. Schwan, G. Caldow, S. Strain, M. Carter, S. Wells, M. Munyeme, R. Wolf, R. Gurung, C. Verdugo, C. Fourichon, T. Yamamoto, S. Thapaliya, E. Di Labio, M. Ekgatat, A. Gil, A. N. Alesandre, J. Piaggio, A. Suanes, and J. H. de Waard. 2019. Control of paratuberculosis: Who, why and how. A review of 48 countries. BMC Vet. Res. 15:198. https://doi.org/ 10.1186/s12917-019-1943-4.

Wickham, H. 2009 ggplot2: Elegant Graphics for Data Analysis. Springer-Verlag, New York, NY.

Wickham, H., R. François, L. Henry, and K. Müller. 2019. dplyr: A grammar of data manipulation. $\mathrm{R}$ package version 0.8.0.1. https:/ /CRAN.R-project.org/package=dplyr.

\section{ORCIDS}

Conor G. McAloon (ํ) https://orcid.org/0000-0002-4984-4031 Bruno Botaro $\odot$ https://orcid.org/0000-0001-7823-6855 Simon J. More @ https://orcid.org/0000-0002-4270-0385 Søren Saxmose Nielsen ® https://orcid.org/0000-0003-2417-0787 Kevin Kenny ๑ https://orcid.org/0000-0002-8339-3641 David Graham ๑ https://orcid.org/0000-0002-6497-0343 Martin Green () https://orcid.org/0000-0002-6408-6443 